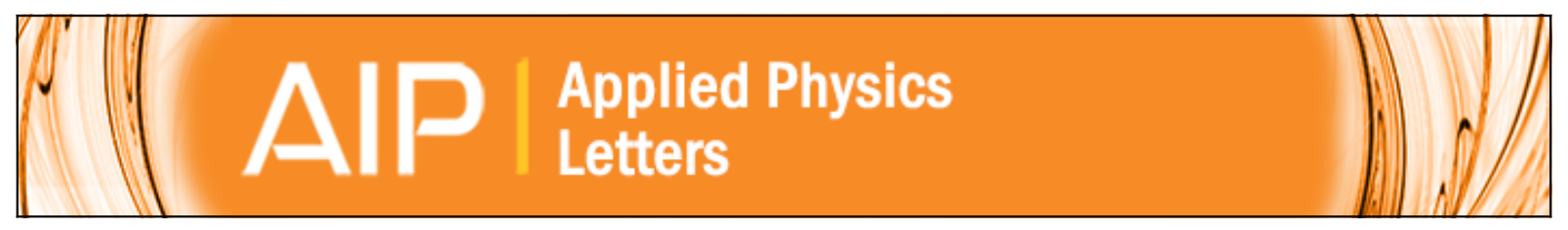

\title{
Photovoltaic effects on the organic ambipolar field-effect transistors
}

Shinuk Cho, Jonathan Yuen, Jin Young Kim, Kwanghee Lee, and Alan J. Heeger

Citation: Applied Physics Letters 90, 063511 (2007); doi: 10.1063/1.2457801

View online: http://dx.doi.org/10.1063/1.2457801

View Table of Contents: http://scitation.aip.org/content/aip/journal/apl/90/6?ver=pdfcov

Published by the AIP Publishing

Articles you may be interested in

Light-emitting organic field-effect transistor using an organic heterostructure within the transistor channel

Appl. Phys. Lett. 89, 223504 (2006); 10.1063/1.2392937

Planar nanoscale architecture for organic thin-film field-effect transistors

Appl. Phys. Lett. 89, 203118 (2006); 10.1063/1.2388569

Effect of light irradiation on the characteristics of organic field-effect transistors

J. Appl. Phys. 100, 094501 (2006); 10.1063/1.2364449

Ambipolar organic field-effect transistors fabricated using a composite of semiconducting polymer and soluble fullerene

Appl. Phys. Lett. 89, 153505 (2006); 10.1063/1.2361269

Noncoplanar organic field-effect transistor based on copper phthalocyanine

Appl. Phys. Lett. 88, 121907 (2006); 10.1063/1.2182016

A|P Applied Physics

A|Petters

is pleased to announce Reuben Collins as its new Editor-in-Chief

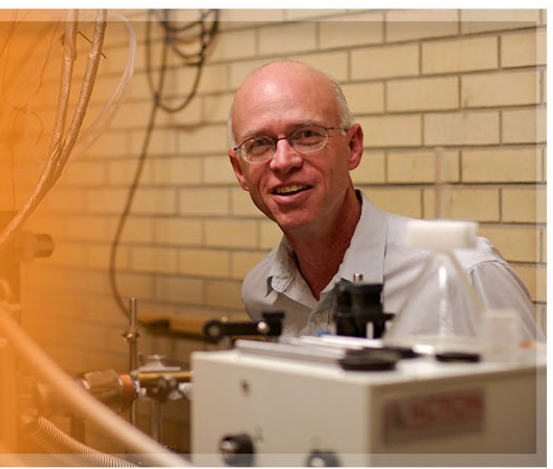




\title{
Photovoltaic effects on the organic ambipolar field-effect transistors
}

\author{
Shinuk Cho, Jonathan Yuen, Jin Young Kim, Kwanghee Lee, ${ }^{a}$ and Alan J. Heeger \\ Center for Polymers and Organic Solids, University of California at Santa Barbara, Santa Barbara, \\ California 93106-5090
}

(Received 5 December 2006; accepted 7 January 2007; published online 8 February 2007)

\begin{abstract}
An organic multifunctional device, which can function as an ambipolar field-effect transistor (FET) and a photovoltaic (PV) cell, has been demonstrated using a phase separated mixture of poly(3-hexylthiophene) and [6,6]-phenyl $\mathrm{C}_{61}$-butyric acid methyl ester. The gold (Au) electrode used for hole injection in the FET mode (source) acts as the anode in PV cell mode, and the aluminum (Al) electrode for electron injection in the FET mode (drain) acts as the cathode in PV cell mode. The device exhibits clear PV phenomena under illumination at zero gate bias with a power conversion efficiency of $0.6 \%$ as well as the properties of an ambipolar FET when the gate bias is applied. (C) 2007 American Institute of Physics. [DOI: 10.1063/1.2457801]
\end{abstract}

Organic electronic devices using conjugated polymers, such as polymer field-effect transistors (p-FETs), ${ }^{1-3}$ polymer light emitting diodes (p-LEDs), ${ }^{4-6}$ and polymer solar cells, ${ }^{7,8}$ have drawn considerable attention as the components of "plastic electronics" because of their promising potential in low-cost portable devices. Recently, as demand for lightweight portable devices increases, multifunctional organic devices, which are integrated with more than two functions, are attractive because such multifunctionality gives an opportunity to achieve lightweight and portable devices by simplifying the design and fabrication processes. Moreover, multifunctionality provides a possibility to create other concepts and devices with other capabilities. ${ }^{9-16}$

Several multifunctional devices using organic materials have been previously reported; for example, the light emitting field-effect transistors (FET) which is the combination of p-LED and p-FET, ${ }^{10-12}$ and the light emitting solar cell which is the combination of p-LED and solar cell. ${ }^{9}$ The ambipolar FET also can be classified as a multifunctional device in a broad sense because it can be operated in two different modes; $p$-type and $n$-type. ${ }^{13-17}$ In order to achieve ambipolarity in organic FETs, blends of hole and electron transporting materials have been used because most organic materials show either higher hole mobility or higher electron mobility. In a previous report, we presented an ambipolar FET using a phase separated mixture of regioregular poly(3-hexylthiophene) (P3HT) and[6,6]-phenyl $\mathrm{C}_{61}$-butyric acid methyl ester (PCBM). ${ }^{17}$

The P3HT and PCBM mixture, in the form of a bulk heterojunction material, was used as the active material for polymer based solar cell. ${ }^{7,8}$ There are, however, big differences in the device structures, and the device operation between ambipolar FETs and solar cells. Thus, it might seem that an integration of an ambipolar FET and a solar cell cannot be possible. The basic difference in operation between solar cells and FETs comes from the creation of potential drop by the work function difference between the two electrodes. For the solar cell, charge carriers can move when they are created by incident light because of the potential

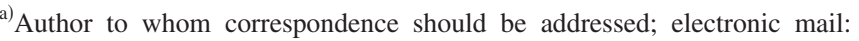
klee@physics.ucsb.edu.

Current address: Gwangju Institute of Science and Technology, Gwangju 500-712, South Korea.
}

drop caused by the work function difference between cathode and anode. On the other hand, because, typically, the same metal has been used as the source and drain electrodes on FET, charge carriers do not flow without a bias between source and drain even if the charge carriers are created by incident light. Although it has been reported that the current between source and drain increases when the FET devices were illuminated, ${ }^{18-20}$ this occurred only under the situation when the bias voltage is applied between source and drain.

In this work, we present the results of studies of the photovoltaic effect on an ambipolar FET using a P3HTPCBM mixture by introducing two different metals for the

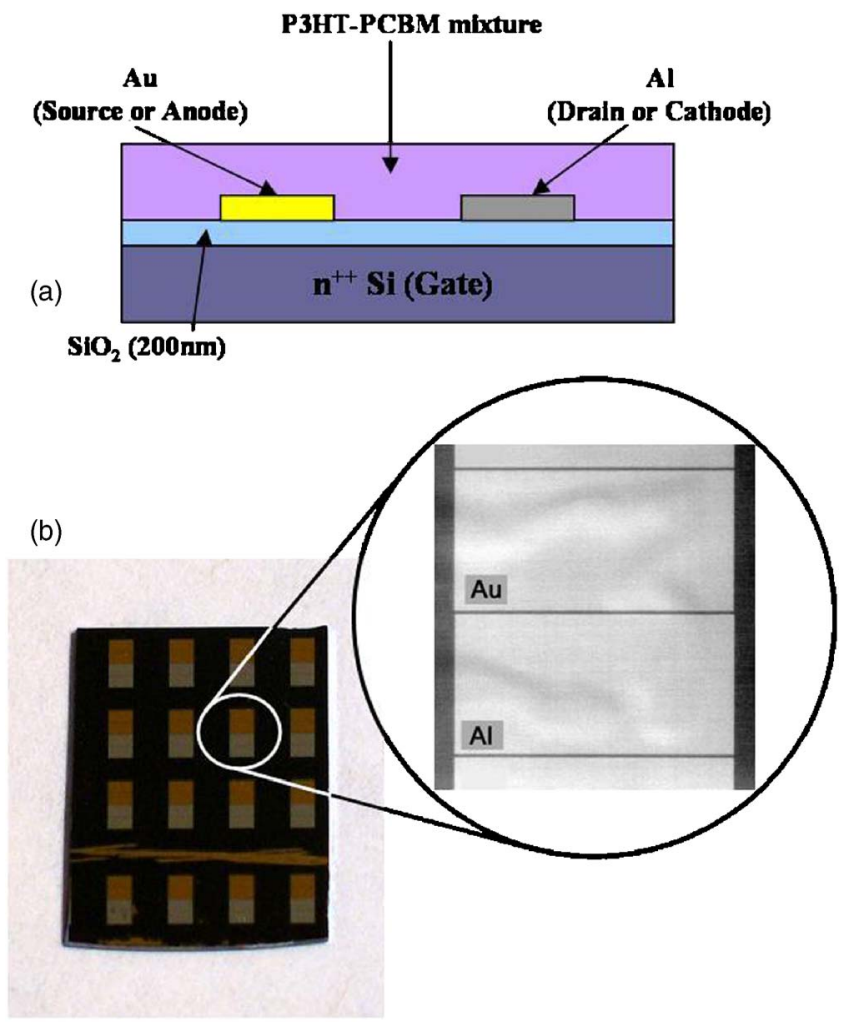

FIG. 1. (Color online) (a) Schematic diagram of device structure using two color electrodes of $\mathrm{Au}$ and $\mathrm{Al}$ for source and drain, respectively. (b) Image of devices fabricated by standard photolithography techniques. In the circular inset, the microscope photograph shows clear gap between two electrodes. 

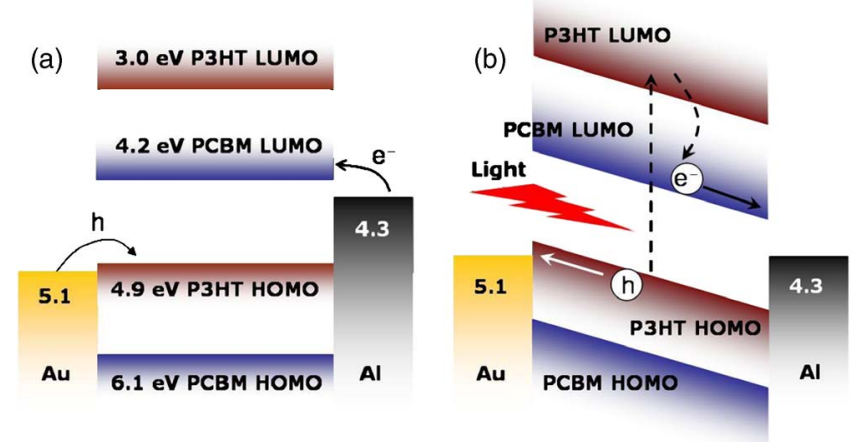

FIG. 2. (Color online) Schematic energy level diagram of the P3HT and PCBM mixture with respect to the work functions of Au and Al. (a) FET operation mode and (b) solar cell operation mode.

source $(\mathrm{Au})$ and drain $(\mathrm{Al})$ electrodes ("two color" electrodes). Because of the work function difference between the two metals, a potential drop is created across the active layer under short circuit condition. The device shows clear photovoltaic effects when illuminated at zero gate bias in addition to the ambipolar FET properties when the gate bias is applied.

FET structures were fabricated on a heavily doped $n$-type $\mathrm{Si}$ wafer with a $200 \mathrm{~nm}$ thick thermally grown $\mathrm{SiO}_{2}$ layer. The doped $n$-type $\mathrm{Si}$ functions as a gate electrode, and the oxide layer functions as the gate dielectric. Source $(\mathrm{Au})$ and drain electrodes $(\mathrm{Al})$ with $50 \mathrm{~nm}$ thickness were deposited onto the $\mathrm{SiO}_{2}$ by e-beam evaporation; the electrodes were patterned using standard photolithographic methods. All devices were made with bottom contact geometry. Figure 1(a) shows the schematic diagram of the device structure and Fig. 1(b) shows an image of the device before the active layer deposition. The circular inset image clearly shows a gap between $\mathrm{Al}$ and $\mathrm{Au}$ electrodes. The channel length was $10 \mu \mathrm{m}$ and the channel width was $1000 \mu \mathrm{m}$.

A mixture of P3HT-PCBM was deposited as the active layer by spin coating at $3000 \mathrm{rpm}$ for $60 \mathrm{~s}$. Before the deposition of the P3HT-PCBM layer, the Al electrodes were etched with standard aluminum etchant to remove the aluminum oxide layer. The mixed solution contained P3HT-PCBM with 1:1 ratio at a concentration of 0.5 wt. \% in chloroform $\left(\mathrm{CHCl}_{3}\right)$. The thickness of P3HT-PCBM film was approximately $60 \mathrm{~nm}$. After active layer deposition, thermal annealing was carried out on a calibrated and stabilized hot plate under $\mathrm{N}_{2}$ atmosphere at $150^{\circ} \mathrm{C}$ for $10 \mathrm{~min}$. After annealing, the devices were put on a metal plate at room temperature for cooling. Electrical characterization was performed using a Keithley semiconductor parametric analyzer (Keithley 4200) under $\mathrm{N}_{2}$ atmosphere.

Figure 2(a) shows schematic energy level diagrams of the highest occupied molecular orbital (HOMO) and lowest occupied molecular orbital (LUMO) of the P3HT and PCBM mixture with the work function of Au and Al for FET operation. In order to achieve ambipolar performance using the P3HT-PCBM mixture, the electrode needs to have a work function that allows injection of holes into the HOMO of P3HT and the injection of electrons into the LUMO of PCBM. For $p$-type operation mode, there is no doubt that efficient injection of holes into the HOMO of P3HT can be achieved by using the Au electrode. Ambipolar FETs using P3HT-PCBM mixture with Al source and drain electrodes
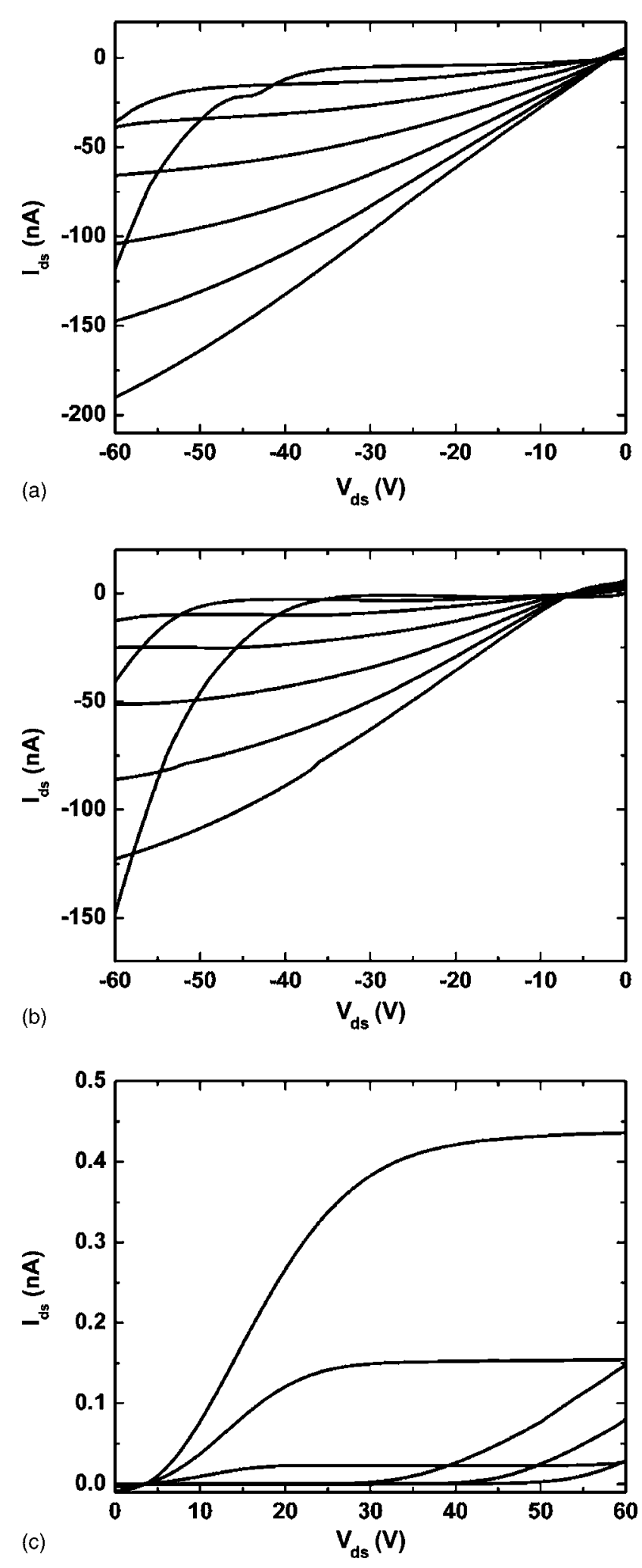

FIG. 3. Ambipolar FET characteristics of $I_{\mathrm{ds}} \mathrm{vs} V_{\mathrm{ds}}$ for (a) $p$-type operation with $\mathrm{Au}$ as the source electrode, (b) $p$-type operation with $\mathrm{Al}$ as the source electrode, and (c) $n$-type operation with $\mathrm{Al}$ as the drain electrode.

were demonstrated in our previous report. ${ }^{17}$ Thus, Al was used for electron injection into the LUMO of PCBM because $\mathrm{Al}$ is much closer to the LUMO of PCBM.

For the solar cell operation, photoexcitation in P3HT is followed immediately by electron transfer to PCBM. However, if there is no potential drop across the active layer, separated holes and electrons cannot move toward the re- 


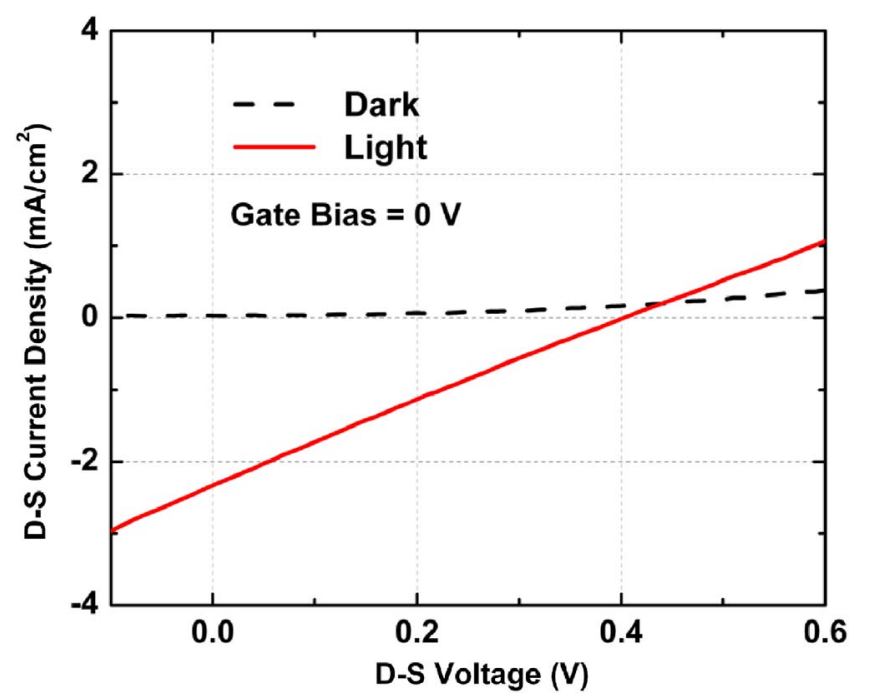

FIG. 4. (Color online) $I-V$ characteristics of the PV-FET in the dark and under illumination with a white light source (tungsten-halogen lamp, $40 \mathrm{~mW} / \mathrm{cm}^{2}$ ) at zero gate bias.

spective electrodes. Thus, in order to make the potential drop between source and drain, we introduced two color electrodes using $\mathrm{Al}$ and $\mathrm{Au}$. Because of the different work functions of $\mathrm{Au}$ and $\mathrm{Al}$, a potential drop is created in the active layer under short circuit conditions [see Fig. 2(b)]. Therefore, separated holes and electrons will flow to the electrodes through the potential drop without bias. Thus, the device can be operated on solar cell mode.

Figure 3 presents the ambipolar characteristics of the drain-source current $\left(I_{\mathrm{ds}}\right)$ versus the drain-source voltage $\left(V_{\mathrm{ds}}\right)$ for $p$-type operation [Figs. 3(a) and 3(b)] and for $n$-type operation [Fig. 3(c)], corresponding to hole and electron accumulations, respectively. At the low gate voltages, the devices show diodelike curves, which are typical of ambipolar transistors. These features occur because of the presence of both hole and electron charge carriers in same channel. At high gate voltages, true $p$ - or $n$-channel behavior begins to appear. For $p$-type operation, the device well operates with both $\mathrm{Al}$ and $\mathrm{Au}$ as the source electrode, as shown in Figs. 3(a) and 3(b). Although there is an energy barrier between the work function of $\mathrm{Al}$ and the HOMO of P3HT, the hole currents are sufficiently large to support $p$-type performance. Of course, the operation with $\mathrm{Au}$ electrode as the source exhibits better $p$-type behavior than the operation with $\mathrm{Al}$ electrode. On the other hand, the $n$-type behavior only appears when $\mathrm{Al}$ was used for the drain electrode because the energy barrier between $\mathrm{Au}$ and the LUMO of PCBM is too large to electron injection.

The ambipolar FET made with two color electrodes exhibits photovoltaic device operation under illumination. Figure 4 shows the $I-V$ characteristics of the device in the dark and under illumination with a white light source (tungsten-halogen lamp, $40 \mathrm{~mW} / \mathrm{cm}^{2}$ ) at zero gate bias.
In the dark, there is no current in zero drain-source bias. However, the $I-V$ curve shows typical photovoltaic features under illumination, with a short circuit current of $I_{\mathrm{sc}}$ $\sim 2.3 \mathrm{~mA} / \mathrm{cm}^{2}$ and an open-circuit voltage of $V_{\mathrm{oc}} \sim 0.4 \mathrm{~V}$. The fill factor of this device is estimated to be about 0.24 , leading to a $0.6 \%$ power conversion efficiency deduced using the standard equation for the efficiency $\left(\eta_{e}\right) ; \eta_{e}$ $=\mathrm{FF}\left(I_{\mathrm{sc}} V_{\mathrm{oc}} / P_{\text {in }}\right)$, where $\mathrm{FF}=\left(I_{m} V_{m} / I_{\mathrm{sc}} V_{\mathrm{oc}}\right)$.

In conclusion, we have demonstrated a multifunctional device which functions both as an ambipolar FET and as a solar cell by using two color electrodes. The device exhibits ambipolar FET properties when the gate bias is applied, and it exhibits PV effects under the illumination at zero gate bias. Although the power conversion efficiency $(\sim 0.6 \%)$ is somewhat lower than the typical organic solar cell in the sandwich configuration, if we consider that the spacing between cathode and anode is $10 \mu \mathrm{m}$, the results are encouraging.

This research was supported by the International Cooperation Research Program of the Ministry of Science \& Technology (M60605000005-06A0500-00510).

${ }^{1}$ H. Sirringhaus, Adv. Mater. (Weinheim, Ger.) 17, 2411 (2005).

${ }^{2}$ H. E. A. Huitema, G. H. Gelinck, J. B. P. H. van der Putten, K. E. Kuijk, C. M. Hart, E. Cantatore, P. T. Herwig, A. J. J. M. van Breemen, and D. M. de Leeuw, Nature (London) 414, 599 (2001).

${ }^{3}$ L. L. Chua, J. Zaumseil, J-F. Chang, E. C.-W. Ou, P. K.-H. Ho, H. Sirringhaus, and R. H. Friend, Nature (London) 434, 194 (2005).

${ }^{4}$ C. W. Tang and S. A. Vanslyke, Appl. Phys. Lett. 51, 913 (1987).

${ }^{5}$ J. Y. Kim, S. H. Park, K. Lee, I. S. Yum, and S. H. Jin, Appl. Phys. Lett. 81, 1732 (2002).

${ }^{6}$ C. D. Müller, A. Falcou, N. Reckefuss, M. Rojahn, V. Wiederhirn, P. Rudati, H. Frohne, O. Nuyken, H. Becker, and K. Meerholz, Nature (London) 421, 829 (2003).

${ }^{7}$ W. Ma, C. Y. Yang, X. Gong, K. Lee, and A. J. Heeger, Adv. Funct. Mater. 15, 1617 (2005).

${ }^{8}$ J. Y. Kim, S. H. Kim, H.-H. Lee, K. Lee, W. Ma, X. Gong, and Alan J. Heeger, Adv. Mater. (Weinheim, Ger.) 18, 572 (2006).

${ }^{9}$ H. Kim, J. Y. Kim, S. H. Park, K. Lee, Y. Jin, J. Kim, and H. Suh, Appl. Phys. Lett. 86, 183502 (2005).

${ }^{10}$ C-W. Chu, C.-W. Chen, S.-H. Li, E. H.-En Wu, and Y. Yang, Appl. Phys. Lett. 86, 253503 (2005).

${ }^{11}$ J. Zaumseil, R. H. Friend, and H. Sirringhaus, Nat. Mater. 5, 69 (2006).

${ }^{12}$ J. S. Swensen, C. Soci, and A. J. Heeger, Appl. Phys. Lett. 87, 253511 (2005).

${ }^{13}$ E. J. Meijer, D. M. De Leeuw, S. Setayesh, E. V. Veenendaal, B.-H. Huisman, P. W. M. Blom, J. C. Hummelen, U. Scherf, and T. M. Klapwijk, Nat. Mater. 2, 678 (2003).

${ }^{14}$ Y. Hayashi, H. Kanamori, I. Yamada, A. Takasu, S. Takagi, and K. Kaneko, Appl. Phys. Lett. 86, 052104 (2005).

${ }^{15}$ K. Tada, H. Harada, and K. Yoshino, Jpn. J. Appl. Phys., Part 2 36, L718 (1997).

${ }^{16}$ A. Babel, J. D. Wind, and S. A. Jenekhe, Adv. Funct. Mater. 14, 891 (2004).

${ }^{17}$ S. Cho, J. Yuen, J. Y. Kim, K. Lee, and A. J. Heeger, Appl. Phys. Lett. 89, 153505 (2006).

${ }^{18}$ V. Podzorov, V. M. Pudalov, and M. E. Gershenson, Appl. Phys. Lett. 85, 6039 (2004).

${ }^{19}$ M. Mas-Torrent, P. Hadley, N. Crivillers, J. Veciana, and C. Rovira, ChemPhysChem 7, 86 (2006).

${ }^{20}$ N. Marjanović, Th. B. Singh, G. Dennler, S. Günes, H. Neugebauer, N. S. Sariciftci, R. Schwödiauer, and S. Bauer, Org. Electron. 7, 188 (2006). 